\title{
MICRÓBIOS NO CONVÉS: A PESTE BUBÔNICA E O FIM DAS QUARENTENAS NO BRASIL (1899 - 1904)
}

MICROBES ON DECK: THE BUBONIC PLAGUE AND THE END OF THE FORTIES IN BRAZIL (1899 - 1904)

\author{
Matheus Alves Duarte da Silva* \\ matheus.duarte9@gmail.com
}

RESUMO: O presente artigo analisa as imbricações entre as epidemias de peste bubônica no Brasil, sobretudo no Rio de Janeiro, e o progressivo relaxamento das leis quarentenárias brasileiras até a extinção da prática da quarentena, em 1904. O artigo argumenta que, em primeiro lugar, a ameaça e, posteriormente, a presença da peste bubônica no país, catalisaram uma discussão profunda sobre a pertinência, ou não, do estabelecimento de quarentenas. E em segundo lugar, que foi a mudança na descrição do comportamento do bacilo da peste em território brasileiro - passando de uma imagem de doença incontrolável e terrível para uma de dominável pelos avanços da civilização - que possibilitou, em conjunto com outros fatores, entre eles os problemas comerciais, a extinção das quarentenas. $\mathrm{O}$ artigo utiliza como fontes a documentação oficial do Ministério da Justiça e Negócios Interiores, e também discussões sobre a temática da quarentena veiculadas em periódicos diários do Rio de Janeiro.

PALAVRAS-ChAVE: Peste bubônica, quarentena, Brasil.

ABSTRACT: The present paper analyses the connections between the bubonic plague epidemics in Brazil, especially in Rio de Janeiro, and the progressive relaxation of the Brazilian quarantine laws until their extinction in 1904. The paper argues that the threat, and later the presence of the bubonic plague in the country provoked a deep discussion about the relevance of the establishment of quarantines. Another important aspect was the change in the behavior of the plague's bacillus in the Brazilian territory - from causing a terrible and incontrollable disease to being surmountable by the advances of civilization -, which, together with other factors, among them some commercial problems, made the extinction of quarantines possible. The paper uses as sources the official documentation of the Ministry of Justice and Internal Affairs, and also discussions about the quarantines published in Rio de Janeiro's daily newspapers.

KEYWORDS: Bubonic plague, quarantine, Brazil.

\footnotetext{
* Mestre em História Social pela Universidade de São Paulo com período sanduíche na École des Hautes Études en Sciences Sociales (Paris), com bolsa BEPE/FAPESP. Editor do Boletim Eletrônico da Sociedade Brasileira de História da Ciência (SBHC).
} 


\section{Introdução}

Os objetivos do artigo são dois. Em primeiro lugar, analisar a construção social da peste bubônica no Brasil, isto é, compreender através da ação de que personagens e elementos a peste bubônica e suas características, tais como o tempo de incubação e a letalidade do bacilo, foram consideradas objetos estáveis e consensuais entre os médicos e políticos brasileiros. Em segundo lugar, compreender como essa estabilização em torno da peste bubônica foi determinante para que a prática de se estabelecer quarentenas e restrições comerciais aos navios saídos de portos contaminados pela doença fosse paulatinamente abrandada, até ser formalmente extinta no Brasil, em 1904.

Epidemias de peste bubônica e a política quarentenária brasileira já foram estudadas, sem que se estabelecesse uma relação profunda entre elas, conforme se procura fazer aqui. Dentre os trabalhos que discutem a presença da doença no Brasil, destacam-se, por ordem cronológica de publicação, o de Nancy Stepan (1976) e o de Jaime Benchimol (1990a), ambos sobre a criação do Instituto Soroterápico Federal em 1900, que visava produzir soro antipestoso para tratar as vítimas da peste, que acabara de surgir no país. No entanto, em ambos os trabalhos, a peste bubônica não ocupa um papel central, posto que o que se pretende discutir é o papel desempenhado pelo Instituto Soroterápico na institucionalização da ciência no Brasil.

Em trabalhos mais recentes, as epidemias de peste bubônica no Brasil foram discutidas para além do viés da fundação do instituto. Dilene Nascimento (2011), por exemplo, analisou, a partir de matérias publicadas em jornais diários, a representação social da peste entre a população paulista e o medo em torno da doença quando da possível chegada da peste àquele estado, em meados de 1899. Em trabalhos anteriores, discuti as mudanças da representação social da peste bubônica no Rio de Janeiro durante o primeiro ano de epidemia na cidade, entre 1900 e 1901 (SILVA, 2012) e como se construiu um consenso político e científico em torno das medidas a serem empregadas para controlá-la na cidade do Rio de Janeiro, entre os anos de 1897 e 1906 (SILVA, 2015).

Por fim, em artigo escrito conjuntamente (NASCIMENTO, SILVA, 2013a), o enfoque foi uma controvérsia entre duas autoridades sanitárias, Nuno de Andrade e Jorge Pinto, ocorrida entre outubro e setembro de 1899, que girou em torno das medidas restritivas adotadas pelo Governo Federal para impedir que a doença chegasse ao país, transportada em navios saídos da cidade do Porto, em Portugal. Nesse artigo, apontamos que tal debate evidenciou insatisfações de setores da população carioca em torno da adoção de quarentenas pelo Governo Brasileiro, mas que vozes dissonantes, como a de Jorge Pinto, 
foram abafadas naquele momento. No presente artigo, procuraremos recuperar alguns pontos da discussão realizada no trabalho anterior, mas inserindo-os em um processo mais longo que culminou com a extinção das quarentenas no Brasil.

O tema das quarentenas, por sua vez, é um clássico na historiografia internacional sobre saúde pública. Em um dos trabalhos mais conhecidos, Erwin Ackerknecht (1949) aponta a relação entre a ideologia política de determinado país e a adoção, ou não, de quarentenas. A Inglaterra, por exemplo, país de tradição liberal, não realizava essa prática, posto que ela feria os interesses comerciais. Esse modelo já foi criticado em outros trabalhos (BALDWIN, 1996), no quais se apresenta não ser possível estabelecer uma correspondência tão linear entre estrutura política e adoção de quarentenas. No entanto, é indiscutível que o trabalho de Ackernecht teve como principal mérito demonstrar que, na adoção, ou não, de práticas quarentenárias, critérios científicos e políticos se misturavam.

Os trabalhos sobre o fim das quarentenas no Brasil, evento ocorrido em 1904, estão submetidos a uma análise conjuntural sobre os primórdios da saúde pública nacional. Por isso, entendem o fim das quarentenas dentro das mudanças pelas quais passava a saúde pública naquele momento. Nesses estudos, as reformulações na legislação sanitária, não apenas no tocante às quarentenas, são entendidas como um desejo das elites políticas brasileiras em reestruturar a questão sanitária com a finalidade de diminuir os prejuízos comerciais e simbólicos que o Brasil sofria por conta das epidemias existentes, sobretudo, na Capital Federal (BENCHIMOL, 1900b; CASTRO SANTOS, 1987; HOCHMAN, 2013).

No presente artigo, sem discordar frontalmente dos trabalhos anteriores, pretendese evidenciar que além dos interesses econômicos, políticos e simbólicos das elites brasileiras, a extinção da prática quarentenária no Brasil esteve intrinsicamente relacionada à ação da peste bubônica em território nacional e, sobretudo, à construção do consenso entre médicos e políticos brasileiros em torno de um aspecto fundamental da doença: o comportamento aparente benigno do bacilo no Brasil. Sem o consenso em torno desse ponto, que tornava quase sem propósito a adoção das quarentenas, elas, provavelmente, teriam permanecido.

\section{A peste e necessidade das quarentenas (1894-1899)}

Segundo informava o Jornal do Commercio de 15 de agosto de 1899, o Governo Brasileiro recebera no dia anterior um telegrama de Lisboa, que informava, oficialmente, 0 aparecimento de casos de peste bubônica na cidade do Porto. 
Pela primeira vez o Brasil se via confrontado com a ameaça direta da chegada da doença ao país, dado o estreito contato existente entre os portos brasileiros e os portugueses. Em fins do século XIX, a doença existia endemicamente na Índia e na China. Em Hong Kong, então colônia inglesa, explodiu, em 1894, uma epidemia de peste bubônica. Foi ali que, naquele ano, dois cientistas, o francês Alexandre Yersin e o japonês Shibasaburo Kitasato afirmaram, separadamente, terem identificado a causa da doença, um bacilo. A partir dessa identificação, abriu-se caminho para que cientistas de diferentes nacionalidades procurassem estudar a maneira pela qual esse bacilo era transmitido ao homem. Entre 1894 e 1899, a partir de pesquisas desenvolvidas na Índia e em Hong Kong, emergiram três teorias para explicar esse fenômeno (HIRST, 1953).

A primeira teoria foi postulada pelos cientistas ingleses Willian Hunter, M. Wilm e Willian Simpson. Esses autores defendiam que o bacilo da peste era transmitido por via digestiva, através de alimentos ou de água contaminada. Os ratos e humanos infectados por peste defecavam no solo e os micróbios eram então levados por moscas, formigas e baratas até os alimentos, que ficavam contaminados. Uma variante dessa teoria afirmava que a peste também poderia ser transmitida através de feridas no pé em contato com o solo contaminado (HIRST, 1953, p. 111-114).

A teoria do contágio/contato ${ }^{1}$ diferia da anterior ao postular que a maior incidência da transmissão da peste não se dava pelo contato do homem com o solo ou com alimentos contaminados, mas sim de homem para homem, através do ar, do contato direto ou de objetos contaminados. Desse modo, a única solução viável para combater a peste seria isolar os doentes, desinfetar suas casas, roupas e pertences, e criar um cordão de desinfecção cujo alvo seria as bagagens de pessoas saídas de locais contaminados (HIRST, 1953, p. 115-117).

Uma terceira teoria, formulada em 1898 por Paul-Louis Simond, cientista do Instituto Pasteur de Paris, afirmava que o bacilo da peste era transmitido, basicamente, pela pulga de ratos contaminados. Para essa teoria, a principal solução seria exterminar os ratos e suas pulgas, e isolar as pessoas contaminadas. As trocas comerciais, por sua vez, não precisavam ser afetadas, posto que para Simond a doença não era transmitida por objetos (SIMOND, 1898).

\footnotetext{
${ }^{1}$ No original, em inglês, "contagion" (HIRST, 1953:115). Segundo o Dicionário Oxford, o significado da palavra é: "The communication of disease from one person to another by close contact". Esta definição traduzida ao português seria: a transmissão de uma doença para outra pessoa por contato direto (tradução nossa). Logo, o contágio pressupõe contato.
} 
Essas três teorias sobre a transmissão da doença circulavam entre os médicos e políticos brasileiros envolvidos no combate a moléstias exóticas, como pode ser verificado a partir da leitura de diferentes artigos publicados sobre tal temática no principal periódico científico brasileiro da época, o Brazil-Medico (CALMETTE, 1899; NERY, 1897, SEIDL, 1898). Dessas três teorias, o Governo Brasileiro estava mais convencido da transmissão da doença por objetos, conforme pode ser verificado nas medidas tomadas contra os navios portugueses implantadas em 15 de agosto de 1899:

O porto de Leixões [nome do porto da cidade do Porto] foi declarado infecto e todos os portos portugueses, continentais e insulares, foram averbados de suspeitos. [...] Todos os navios partidos de portos portugueses ficaram sujeitos a quarentena de 20 dias, ${ }^{2}$ [...] como ficaram sujeitos a desinfecções rigorosas, [...] estendendo a suspeição sanitária ao porto espanhol de Vigo, [...] aos portos de Corunha, Santander e Bilbao, como aditou ao interdito dos gêneros portugueses (BRASIL, 1900, p. 349).

Os produtos suspeitos de transportarem o bacilo da peste e proibidos de desembarcar no Brasil, vindos dos referidos portos, estão listados no Jornal do Comercio, edição de 16 agosto:

Encomendas postais que ocultem, pelos seus invólucros, a espécie remetida, couros e peles, mobílias e guarnições usadas, de sala e quarto; roupas de uso e seus acessórios, que não pertençam à bagagem de passageiros; peles e outros despojos animais, frutas e laticínios, retalhos de fazenda ou trapos.

Tais medidas foram tomadas pela Diretoria Geral de Saúde Pública (DGSP). A DGSP era ligada ao Ministério da Justiça e Negócios Interiores e sua função principal era evitar a chegada ao país de moléstias exóticas, possuindo, por exemplo, o poder de decretar quarentenas sobre navios nacionais e estrangeiros e proibir a importação de mercadorias do exterior. No território nacional sua atuação era interditada graças ao pacto federalista e ela só poderia intervir ali caso as autoridades estaduais solicitassem (HOCHMAN, 2013, p. 93). Quem controlava esse órgão era Nuno Ferreira de Andrade, antigo conselheiro do Império, que assumira a direção desde o momento de criação da DGSP, em fevereiro de 1897. Nuno de Andrade era um personagem conhecido entre os médicos e cientistas

\footnotetext{
${ }^{2} \mathrm{O}$ termo quarentena originalmente designava, na Idade Média, o período de 40 dias a que os navios vindos de áreas contaminadas pela peste negra deveriam ficar isolados até poderem entrar nas possessões de Veneza (MACKOWIAK, 2012, p.1071). Em português, segundo o dicionário Aurélio, quarentena significa: "Período, outrora de 40 dias, durante o qual indivíduos provenientes de regiões onde reina doença contagiosa grave permanecem incomunicáveis". Portanto, o estabelecimento de uma quarentena de vinte dias não se tratava de um contrassenso, mas o período de tempo no qual os navios e seus passageiros deveriam ficar incomunicáveis.
} 
brasileiros, pois, além do cargo de Diretor Geral de Saúde Pública, acumulava o posto de lente da 1ạ cadeira de Clínica Médica da Faculdade de Medicina do Rio de Janeiro. ${ }^{3}$

Alguns dias após a publicação das medidas mencionadas acima, em 24 de agosto de 1899, o Jornal do Commercio veiculou na primeira página uma carta intitulada "Estado do Rio". Ela era assinada pelo médico Jorge Alberto Leite Pinto, Diretor de Higiene e Assistência Pública, órgão responsável pela saúde pública no Estado do Rio de Janeiro, separado juridicamente da Capital Federal naquele momento. O texto publicado pelo periódico criticava as medidas quarentenárias adotadas pelo Governo Federal contra os navios portugueses (PINTO, 1899a).

Não entraremos em maiores detalhes sobre os argumentos de Jorge Pinto, porque essa controvérsia foi discutida detalhadamente em outro trabalho (NASCIMENTO, SILVA, 2013a). Cabe destacar, apenas, alguns dos principais pontos levantados por ele para fazer face às quarentenas. Em primeiro lugar, ele não acreditava que o período de incubação do bacilo da peste fosse superior a dez dias, o que teria sido comprovado por experiências realizadas na Índia por Simond. Se isso fosse verdade, então uma quarentena de vinte dias seria insensata. Em segundo lugar, Jorge Pinto acreditava ser a peste uma moléstia facilmente dominável pela higiene e que ela se desenvolveria no Brasil de maneira menos letal que o observado na Índia, uma vez que no Brasil se conhecia os pressupostos da higiene moderna. Por fim, Pinto afirmava que o Governo Federal não deveria sancionar medidas sanitárias que criassem prejuízos comerciais (PINTO, 1899a; 1899b).

Esses pontos foram defendidos em uma série de cartas publicadas no Jornal do Commercio entre agosto e setembro de 1899 (NASCIMENTO, SILVA, 2013a). Nesse mesmo período, Nuno de Andrade, também utilizando as páginas do periódico, rebateu os argumentos de Jorge Pinto. Para o Diretor Geral de Saúde Pública, o bacilo da peste tinha um período de incubação extremamente incerto, e a prudência diante dessa incerteza e dos males que poderiam advir da chegada da doença ao Brasil tornava legítimo o Governo Federal estabelecer quarentenas de vinte dias, mesmo que elas gerassem prejuízos comerciais (ANDRADE, 1899a).

Em fins de setembro, esse debate foi concluído com uma vitória de Nuno de Andrade, gerando uma manutenção das quarentenas de vinte dias e da proibição de importação de determinadas mercadorias (NASCIMENTO, SILVA, 2013a). Entretanto, a crença na eficácia dessas medidas sofreu um duro golpe em 15 de outubro de 1899, quando o Governo Federal recebeu a notícia de que na cidade de Santos, litoral paulista,

\footnotetext{
${ }^{3}$ Para uma pequena biografia sobre Nuno de Andrade, consultar o DICIONÁRIO HISTÓRICO-BIOGRÁFICO DAS CIÊNCIAS DA SAÚDE NO BRASIL (1832-1930).
} 
foram registrados casos de uma doença desconhecida cujos sintomas lembravam os da peste bubônica. No dia 19 de outubro, exames bacteriológicos coordenados por Adolpho Lutz, diretor do Instituto de Bacteriologia de São Paulo, confirmaram se tratar da doença (BRASIL, 1900, p. 353). Nesse mesmo dia, o Governo Federal tomou as seguintes medidas contra o porto e a cidade de Santos, segundo o relatório do Ministro da Justiça Epitácio Pessoa:

Eram fechados os outros portos nacionais a todas as procedências de Santos. [...] Praticando o isolamento, voluntário ou não, dos acometidos, sequestrando as respectivas famílias, desinfetando rigorosamente as casas, restringindo as comunicações com as localidades indemnes, [...] criando ao derredor da cidade infectada o mais útil dos cordões sanitários, que é o mantido pela polícia dos trens de ferro (BRASIL, 1900, p. 353 e 357).

Essas medidas eram mais contundentes do que as tomadas contra o Porto. Os navios saídos de Santos não tinham que se submeter a uma quarentena de vinte dias. Estavam, na verdade, proibidos de tocar qualquer porto nacional e os navios saídos de outros portos brasileiros proibidos de ancorar naquele porto. Por outro lado, a exportação de café manteve-se, uma vez que Santos recebia a mercadoria pelas estradas de ferro. ${ }^{4}$

O aparecimento de casos de peste bubônica em Santos e a adoção de medidas contra o porto da cidade gerou problemas para os habitantes e aqueles envolvidos com o comércio marítimo daquela cidade. O local onde esses problemas foram gerados era 0 laboratório onde Adolpho Lutz identificou o bacilo da peste no sangue dos habitantes de Santos mortos pela doença misteriosa. Uma contestação a essa afirmação só poderia vir de outro laboratório. Para tanto, a Câmara Municipal de Santos convidou e comissionou o médico Chapot Prevost, professor da faculdade de Medicina do Rio de Janeiro, para que realizasse investigações bacteriológicas na cidade. ${ }^{5} \mathrm{O}$ Governo Federal também procurou uma segunda opinião e enviou Oswaldo Cruz a Santos. Após a identificação do bacilo no sangue de algumas vítimas, ambos confirmaram ser a peste bubônica a doença que grassava na cidade (BRASIL, 1900, p. 354-355).

As autoridades municipais de Santos tentaram desfazer a rede que garantia a aplicação das medidas sanitárias contra a cidade atacando um dos seus pontos, o bacilo da peste. Ele, no entanto, resistiu aos testes. Restou a elas, sobretudo à Associação Comercial de Santos, pressionarem diretamente o Governo Federal. Enviou-se ao Ministro Epitácio Pessoa, e até ao próprio Presidente da República, Campos Salles, telegramas e solicitações

\footnotetext{
${ }^{4}$ A Associação Comercial de Santos publicou na primeira página do jornal O Estado de São Paulo, edição de 26/10/1899, informando que as exportações de café estavam mantidas.

${ }^{5}$ Notícia sem autoria publicada no Brazil-Medico, edição 41 de 1ํ de novembro de 1899, página 404.
} 
para que as medidas quarentenárias fossem atenuadas (SANTOS, 1902, p. 11). Tal estratégia deu resultados. Em 28 de outubro de 1899, os navios voltaram a comercializar com Santos, desde que efetuassem a descarga das mercadorias sobre água e depois se submetessem a quarentenas no lazareto da Ilha Grande. Continuava proibido o embarque de passageiros e de mercadorias saídas de Santos (BRASIL, 1900, p. 360-361). Em 21 de dezembro, o porto de Santos foi totalmente reaberto, restando aos navios dali saídos o regime quarentenário de vinte dias.

O que provocou o abrandamento de algumas medidas impostas ao porto de Santos foram os seguintes motivos, segundo o relatório do Ministro Epitácio Pessoa: "a clausura dos portos para as procedências de Santos, entretanto, causou profundo abalo nas relações comerciais dessa importante praça e começou a alterar as condições de vida da população, quanto ao suprimento de gêneros de primeira necessidade, como os alimentícios" (BRASIL, 1900, p. 360).

Entretanto, a questão comercial não parece ter sido a única responsável pelo abrandamento das medidas impostas contra Santos. Segundo Nuno de Andrade, elas puderam ser reformuladas porque:

A providência da clausura dos portos nacionais às procedências de Santos, (...) teve o caráter excepcional das medidas de que cogita o art. 64 do regulamento vigente e exprimiu uma necessidade administrativa, criada por moléstia desconhecida entre nós, cujo caráter de benignidade não podia ser pressentido (BRASIL, 1900, p. 361, grifo nosso).

\section{Reconstruindo a peste e relaxando as quarentenas (1900-1904)}

Em 14 de janeiro de 1900, o jornal carioca O Paiz anunciava o aparecimento do primeiro caso confirmado de peste bubônica na cidade do Rio de Janeiro e apresentava algumas das medidas tomadas pelo Governo Federal para fazer frente a esse novo problema:

$1^{\circ}$ Declarar suspeito o porto do Rio de Janeiro; $2^{\circ}$ determinar que os navios saídos com destino aos outros portos nacionais sigam diretamente para o lazareto da Ilha Grande a fim de serem desinfetados, e só sejam recebidos em livre prática nos ditos portos depois de decorridos $\mathbf{1 0}$ dias, contados da data de desinfecção e de verificada a sua perfeita indemnidade; $3^{\circ}$ dispor que se proíba a exportação 
para os referidos portos dos objetos suscetíveis indicados no art. 30 do regulamento sanitário vigente (grifo nosso).

Essas três medidas parecem semelhantes àquelas empregadas quando do surgimento da peste na cidade do Porto e em Santos, discutidas anteriormente: suspeição do porto do Rio de Janeiro, proibição aos outros portos nacionais de importarem as "mercadorias suscetíveis" de conterem o bacilo da peste e quarentena para os navios saídos do porto suspeito. No entanto, se voltarmos ao fragmento retirado d'O Paiz, observaremos uma mudança nas medidas quarentenárias, uma vez que o tempo de quarentena - alvo de controvérsia no ano de 1899 - a que seriam submetidos os navios saídos do porto do Rio de Janeiro foi reduzido de vinte para dez dias. A que se deveu tal alteração?

No relatório do Ministro da Justiça e Negócios Interiores, Epitácio Pessoa, publicado em março de 1900, não existe nenhuma explicação para a mudança do período de quarentena dos navios. $O$ documento apenas informa que as pessoas que tiveram contato com o menino Alcides, o primeiro caso diagnosticado de peste no Rio de Janeiro, também ficaram isoladas durante dez dias e não os vinte que constavam no regulamento sanitário vigente (BRASIL, 1900, p. 363). No entanto, as autoridades federais pareciam não estar convencidas totalmente da alteração do tempo de incubação do bacilo, tanto que preferiram esperar vinte, e não dez dias, a partir da notificação deste primeiro caso, conforme determinava o mesmo regulamento, para considerar, segundo Epitácio Pessoa, em 27 de janeiro: "limpa a cidade do Rio de Janeiro e limpo o respectivo porto" (BRASIL, 1900, p. 363).

A mudança no tempo de quarentena imposto aos navios saídos do porto do Rio de Janeiro revela uma alteração na compreensão, por parte das autoridades sanitárias, das características do bacilo da peste bubônica. Os vinte dias de quarentena haviam sido justificados por Nuno de Andrade por conta de três situações: experimentos realizados por pesquisadores estrangeiros foram incapazes de estabelecer consensualmente o período de incubação máximo da peste bubônica, que oscilava nesses trabalhos entre quatro e vinte dias; a prudência diante dos problemas enfrentados pelos países que adotaram a quarentena de dez dias contra a peste; e o Regulamento Sanitário Brasileiro, que ditava que o período de quarentena contra a peste era de vinte dias. Dessas três razões, nenhuma se alterou entre outubro de 1899 e janeiro de 1900. O Regulamento continuava o mesmo (BRASIL, 1900), nenhum novo experimento havia conseguido dissipar as dúvidas sobre o tempo de incubação do bacilo da peste e o argumento da prudência continuava válido, pois a peste ainda grassava em Portugal (NASCIMENTO; SILVA, 2013b). 
Se as razões para a mudança do tempo de quarentena não podem ser encontradas em um enfraquecimento dos aliados alistados por Nuno de Andrade, talvez possam ser encontradas em um fortalecimento daqueles mobilizados por Jorge Pinto. Os aliados convocados por esse último eram: as experiências de Paul-Louis Simond sobre o tempo de incubação, a benignidade do bacilo da peste observada em Portugal e os prejuízos comerciais causados pelas quarentenas. O primeiro aliado não se fortaleceu entre outubro de 1899 e janeiro de 1900, pois Paul-Louis Simond não publicou novo artigo apresentando provas definitivas sobre o tempo de incubação do bacilo. ${ }^{6}$ Quanto aos outros aliados convocados por Jorge Pinto, a situação fora diferente, conforme veremos.

Apesar de o Governo Federal acreditar que a doença havia sido controlada na Capital da República, novos casos da doença surgiram em abril de 1900 (BRASIL, 1901a, p. 312). Nessa segunda aparição, a mudança nas medidas impostas aos navios saídos do Rio de Janeiro foram maiores, não ficando submetidos a quarentenas, embora permanecesse a restrição ao transporte de mercadorias consideradas capazes de transmitir o bacilo da doença (BRASIL, 1901a, p. 313). Dessa vez, o Ministro Epitácio Pessoa, em relatório publicado em 1901, forneceu razões para isso, alegando que: "entendeu o governo não convir pôr em prática as medidas restritivas do regulamento sanitário quanto aos interditos e quarentenas, de tão perturbadora influência nas relações gerais e tão nocivas aos interesses econômicos do país" (BRASIL, 1901a, p. 313).

A invocação de perturbação nos interesses econômicos já havia sido fornecida pelo mesmo Ministro quando foi decretado o fechamento do porto de Santos, em outubro de 1899. Ora, se tais medidas tomadas contra o porto de Santos representaram um grave prejuízo econômico para aquela localidade, o que aconteceria se fossem aplicadas ao maior porto do país, o do Rio de Janeiro? Se o porto do Rio de Janeiro fosse fechado pelas autoridades federais, provavelmente a economia brasileira entraria em colapso, uma vez que grande parte das importações brasileiras era primeiramente desembarcada nele para depois ser enviada aos outros portos nacionais, e a maioria das exportações nacionais, inclusive de café, era enviada ao exterior por ali (LOBO, 1978).

Em 21 de maio de 1900, quando o número de casos da doença aumentou na cidade do Rio de Janeiro, o Governo Federal foi obrigado a declarar a "existência da peste na Capital Federal" (BRASIL, 1901a: 313). Nesse momento, tal qual em abril, os navios saídos do Rio de Janeiro ficaram livres das quarentenas e a razão invocada foi novamente

\footnotetext{
${ }^{6}$ Após a publicação da monografia de 1898 , em que postula ser a peste transmitida pela pulga do rato, Simond voltaria a publicar trabalhos sobre a peste em agosto de 1900 no XIII Congresso Internacional de Medicina, realizado em Paris. Os trabalhos apresentados ali foram publicados em 1901 (YERSIN; SIMOND, 1901).
} 
questões comerciais: "para não embaraçar a nossa navegação de cabotagem nem prejudicar em excesso a vida material comum", nas palavras do Ministro Epitácio Pessoa (BRASIL, 1901a, p. 314).

Portanto, em 1900, o Governo Federal confessava que as quarentenas impostas aos navios saídos do Rio de Janeiro e suspeitos de transportarem o bacilo da peste bubônica trariam graves prejuízos econômicos, abalando a relação entre os estados da federação. Entretanto, alguns meses depois, o Governo Federal foi obrigado a voltar atrás, por ação dos próprios governos estaduais:

Foram tantas as reclamações dos governos [estaduais] no sentido da decretação de quarentenas e tão impressionante a referência feita ao terror público no tocante à propagação da peste, que mesmo como medida de ordem, resolveu o governo aditar às providências sobre desinfecções a exigência de quarentena de dez dias (BRASIL, 1901a, p. 314).

Se, por um lado, os interesses comerciais pareciam fazer pender a balança para um relaxamento das medidas quarentenárias, por outro havia um elemento que justificaria a adoção das quarentenas: o medo da população brasileira diante da peste. E de onde viria esse temor, uma vez que a doença não existia no Brasil até 1899? Provavelmente, ele decorria da veiculação de informações sobre as epidemias de peste que aconteciam naquele momento na Ásia. Apesar de ser um local distante do Brasil, os jornais de circulação diária no Rio de Janeiro publicavam constantemente telegramas das localidades atingidas, nos quais eram apresentados os elevados números de óbitos que a doença provocava.

Além do Oriente, o medo da peste no Brasil em fins do século XIX vinha, provavelmente, das epidemias ocorridas na Europa durante a Idade Média e Moderna, que construíram um imaginário terrível associado à doença. ${ }^{7} \mathrm{~A}$ existência dessa associação pode ser observada na seguinte explicação dada por Epitácio Pessoa para a falta de notificações de casos de peste bubônica no Rio de Janeiro, no início de 1900: "em virtude da persuasão errônea, ainda não desarraigada de muitos espíritos, de que a epidemia do Levante [peste bubônica] tem a obrigação de revestir a feição devastadora que as descrições pavorosas da peste na Idade Média Ihe imprimiram" (BRASIL, 1901a, p. 313).

O que é interessante notar é como esse imaginário associado à peste produziu efeitos diferentes. Quando o bacilo da peste não existia no Brasil, era interessante para o

\footnotetext{
${ }^{7}$ A associação da peste bubônica com eventos terríveis pode ser percebida até os dias de hoje, pelo uso conferido à palavra "peste" para se referir a tragédias, não necessariamente provocadas por uma doença. Um dos principais exemplos disso é o romance $A$ peste, de Albert Camus.
} 
Governo Federal utilizar o medo para justificar as medidas tomadas, resumidas no aforismo latino ad extremum morbus, extrema remedia, citado por Nuno de Andrade em entrevista publicada em 2 de setembro de 1899 no Jornal do Commercio (ANDRADE, 1899a, p. 1). Quando diversos casos da doença começaram a ser registrados no Rio de Janeiro, entre maio e junho de 1900, o medo da peste gerou problemas para o Governo Federal, pois as autoridades estaduais pediram para que fossem adotadas medidas restritivas contra os navios saídos do Rio de Janeiro. E esse pedido estava baseado em uma visão da peste como moléstia terrível. A solução encontrada pelas autoridades sanitárias federais foi deslegitimar o "terror público" diante da peste, conforme aparece no seguinte trecho do relatório do Ministro Epitácio Pessoa: "convencido de haver voltado aos espíritos uma relativa tranquilidade, aproveitou-se o governo [...] para suprimir, a 10 de outubro [de 1900], as quarentenas" (BRASIL, 1901a, p. 315, grifo nosso).

Essa citação abre caminho para uma compreensão de uma segunda razão - além dos prejuízos econômicos - para o progressivo fim das quarentenas impostas aos navios saídos de portos onde houvesse vítimas do bacilo da peste. Não apenas a ação dos políticos com o objetivo de não prejudicar o comércio marítimo brasileiro, mas também graças ao comportamento do bacilo da peste bubônica em território nacional, conforme já havia sido sinalizado por ocasião do abrandamento das medidas em Santos. Isso porque, ao contrário do que ocorria na Ásia, onde a doença matava aos milhares, apenas 24 pessoas tiveram suas mortes reputadas ao bacilo da peste nas cidades de Santos e de São Paulo, em fins de 1899 e início de 1900 (BRASIL, 1900, p. 363), e 295 no Rio de Janeiro, durante o ano de 1900 (SILVA JUNIOR, 1942, p. 16). ${ }^{8}$ Os números de casos no Brasil mantinham um padrão semelhante ao observado em Portugal ${ }^{9}$ e também em Assunção, no Paraguai (BRASIL, 1900, p. 363). Mas por que o bacilo se comportava em São Paulo e no Rio de Janeiro de maneira distinta do observado na Ásia? Nas palavras de Epitácio Pessoa, porque:

Nos países ocidentais, onde o desenvolvimento da civilização infiltrou [...] os hábitos de asseio e higiene, e bem assim instalou o uso de dispositivos sanitários, perfeitos ou regulares, a moléstia encontra pouco alento, a agressão higiênica é profícua e a expansão epidêmica sempre trôpega. [...] Quem se recorda das descrições trágicas de outrora, ou considera somente os estragos que ela continua a fazer em certas localidades da Índia, mal compreende que seja essa a moléstia que invadiu Portugal, o Paraguai, o Brasil (BRASIL, 1900, p. 356-357).

\footnotetext{
${ }^{8}$ Para efeito de comparação e desprezando as diferenças populacionais, em 1900, em Bombaim, pereceram de peste 15.796 e, em toda a Índia, 139.009 pessoas (ARNOLD, 1993, p. 201).

${ }^{9}$ Entre junho de 1899 a janeiro de 1900, morreram de peste no Porto 115 de um total de 323 pessoas contaminadas (FERRAN; VIÑAS Y CUSI; GRAU, 1907, p. 103).
} 
Ou seja, empregando um argumento semelhante ao de Jorge Pinto (1899a), Epitácio Pessoa afirmava que o Brasil possuía algo que as localidades atingidas na Índia não tinham: a civilização ocidental e os conhecimentos de higiene. E era justamente a posse dessas qualidades que para o Ministro da Justiça impediam o bacilo de se desenvolver no Brasil da mesma maneira que ele se comportava na Ásia. Essa benignidade do bacilo, constatada pelo Governo Federal graças ao pequeno número de óbitos, possibilitava que as quarentenas fossem relaxadas. Se acaso o bacilo da peste tivesse se comportado de maneira diferente no Brasil, matando milhares de pessoas em Santos ou na Capital Federal, como fazia na Índia, será que o "terror público" não teria se intensificado e justificado o fechamento do porto do Rio de Janeiro?

\section{O fim das quarentenas}

Em 9 de março de 1901, o Rio de Janeiro foi novamente declarado limpo de peste bubônica, mas em 26 de setembro daquele ano novos casos foram confirmados na Capital Federal (BRASIL, 1902a, p. 290). Quatro dias depois, foi adotado pelo Governo Federal um novo plano para conter o espraiamento do bacilo da peste bubônica pelo território nacional: os navios saídos do Rio de Janeiro seriam desinfetados, levariam um médico a bordo, mas apenas os navios onde houvesse casos confirmados de peste bubônica seriam submetidos à quarentena de dez dias e a vigilância sobre os passageiros ficaria a cargo das autoridades estaduais (BRASIL, 1901b, p. 1). ${ }^{10}$

Juntamente a essas medidas, a partir de 30 de setembro de 1901, o tempo de quarentena para os navios saídos de portos contaminados pela peste seria oficialmente reduzido por decreto presidencial, no qual se lia "o Presidente da República, atendendo à conveniência de harmonizar os interesses da saúde pública com os do comércio e da navegação, resolve reduzir a dez dias o prazo quarentenário para a peste, alterando-se, nesta parte, o Regulamento Sanitário Federal" (BRASIL, 1901c, p. 1). Campos Salles apenas institucionalizava o período de quarentena para a peste bubônica que vinha sendo utilizado desde janeiro de 1900, conforme discutido antes, e apontava novamente as razões comerciais para a realização de tal mudança. Por fim, uma consequência desse

\footnotetext{
${ }^{10}$ Apesar dessas alterações na legislação quarentenária, as desinfecções e a proibição de transportar determinados produtos se mantiveram. Uma mudança nessa prática começaria a ocorrer a partir de 1903, quando se tornou consenso entre as autoridades sanitárias federais que a transmissão da peste estava ligada diretamente aos ratos e pulgas e que, portanto, tornava-se mais profícuo combater esses animais dentro dos navios vindos de portos contaminados (SILVA, 2015).
} 
decreto era a modificação da compreensão do tempo de incubação do bacilo, agora colocado, também, em dez dias. Curiosamente, essa alteração no Brasil não foi resultado de nenhum trabalho científico, mas de um decreto presidencial.

A justificativa para as mudanças na política quarentenária devia-se, nas palavras do novo Ministro da Justiça e Negócios Interiores, Sabino Barroso, ao fato de que:

A navegação interestadual luta com sérias dificuldades decorrentes da convalescença de uma longa moléstia financeira que abalou o comércio e amesquinhou a atividade das indústrias. [...] A quarentena é um ônus pesadíssimo: obriga a despesas extraordinárias, rasga o cálculo dos roteiros. [...] A quarentena imposta aos navios saídos do porto desta Capital para os portos dos Estados seria um desastre, talvez mais cruel do que a epidemia que se queria evitar (BRASIL, 1902a, p. 298).

Internacionalmente, a prática da quarentena também caminharia para um fim com a realização da Conferência Sanitária Internacional de Paris, entre outubro e dezembro daquele ano, e contando com a participação brasileira. Esta reunião buscava codificar as principais discussões das dez Conferências Sanitárias precedentes ${ }^{11}$ e atualizar as disposições sanitárias internacionais diante das novidades científicas sobre a peste, o cólera e a febre amarela. No que concerne à peste bubônica, as resoluções da Conferência reduziram o período de incubação de dez para cinco dias e permitiu-se aos países signatários que decidissem se decretariam quarentenas para os navios contaminados ou se optariam pela prática da vigilância dos passageiros desembarcados (MONOD, 1904, p. 610).

As resoluções da Conferência de Paris abriram caminho para a extinção da prática da quarentena em nível internacional, o que seria confirmado também no Brasil a partir de junho de 1904. No dia 5 daquele mês, reuniram-se no Rio de Janeiro delegados do Uruguai, Argentina e Paraguai. O Brasil, país anfitrião, era representado por Oswaldo Cruz, naquele momento Diretor Geral de Saúde Pública, e Antônio Augusto Azevedo Sodré, professor da Faculdade de Medicina do Rio de Janeiro (BRASIL, 1905:8). Alguns dias depois, em 12 de junho, os representantes dos quatro países assinaram uma convenção sanitária que tinha como principais focos as medidas a serem adotadas pelos signatários em caso de surgimento de casos de peste bubônica, febre amarela e cólera em seus territórios (BRASIL, 1905:7-20). Segundo o relatório de J.J. Seabra, Ministro da Justiça e Negócios

\footnotetext{
${ }^{11}$ As Conferências Sanitárias Internacionais anteriores foram as seguintes, em ordem cronológica: Paris (1851), Paris (1859), Constantinopla (1866), Viena (1874), Washington (1881), Roma (1885), Veneza (1892), Dresden (1893), Paris (1894), Veneza (1897) (HOWARD-JONES, 1975, p. 5).
} 
Interiores que substituiu Sabino Barroso, a principal resolução do encontro foi acabar "de vez com as odiosas práticas quarentenárias" e as razões para isso é que elas, "além dos prejuízos materiais que acarretavam, constituíam uma perene causa de atritos e desarmonia nas relações internacionais" (BRASIL, 1905, p. 15-16).

\section{Considerações Finais}

A descrição dos primeiros anos de epidemia de peste no Rio de Janeiro mostram duas alterações. A primeira, na compreensão de como se comportava o bacilo da peste bubônica no Brasil: se até 1899 o Governo Federal entendia que ele ficava incubado no homem por um período de vinte dias, a partir de 1900 passou a ser entendido que esse período era de dez dias, o que seria confirmado por decreto presidencial em setembro de 1901. Se em 1899 o bacilo era entendido como terrível, por exemplo, por Nuno de Andrade, a partir de 1900 passou a ser descrito por autoridades federais, entre elas Epitácio Pessoa e o próprio Nuno de Andrade, como controlável, pois o Brasil fazia parte da civilização ocidental e possuía as ferramentas de higiene para lidar com ele.

Tais mudanças na descrição do bacilo alteraram, também, a percepção, por parte do Governo Federal, da necessidade da aplicação das quarentenas. Se em 1899 elas eram entendidas como a principal arma para lutar contra a peste bubônica, apesar dos prejuízos causados, a partir de 1900 passaram a ser vistas como um entrave ao comércio e às relações estabelecidas entre os componentes da federação brasileira, até serem extintas em junho de 1904.

Erwin Ackerknecht (1948), no citado texto sobre a temática das quarentenas, alude a uma relação entre o sistema político e econômico do país e a utilização ou não de quarentenas. O sistema político e econômico brasileiro não se alterou entre 1899 e 1904 . Ou seja, não se deve buscar a explicação para o fim das quarentenas no Brasil ${ }^{12}$ somente em uma relação imediata com o sistema político-econômico, mas sim acompanhar de modo mais amplo o processo que levou a extinção das quarentenas, conforme foi feito nesse artigo. Percebe-se, assim, que esse processo ocorreu graças a diferentes causas, isto é: tanto os problemas econômicos, elevação dos preços dos gêneros alimentícios e

\footnotetext{
${ }^{12}$ Apesar de extintas, as quarentenas foram aplicadas em momentos críticos da história brasileira, como por ocasião da epidemia de gripe espanhola em 1918 e 1919 (RIBELO, 2013, p. 791).
} 
desestabilização da navegação de cabotagem quanto o comportamento relativamente benigno do bacilo da peste bubônica no Brasil. Sem esse comportamento, dificilmente o Governo Federal teria afrouxado e posteriormente extinguido as quarentenas.

\section{REFERÊNCIAS BLIBLIOGRÁFICAS}

ACKERKNECHT, E. H. The Fielding H. Garrison lecture: anticontagionism between 1821-1867. Bulletin of History of Medicine. Baltimore, v.22, p. 562-593, 1949.

ANDRADE, N. de. Peste bubônica. Jornal do Commercio. Rio de Janeiro, 2 set. 1899a, Gazetilha, p. 1-2.

A peste bubônica em Santos. Brazil-Medico. Rio de Janeiro, no 42, p 411-413, nov. 1899b.

ARNOLD, D. Colonizing the Body: State Medicine and Empire Disease in Nineteenth-Century India. Los Angeles: University of California Press, 1993.

BALDWIN, P. Contagion and the state in Europe 1830-1930. New York: Cambridge University Press, 1999.

BENCHIMOL, J. Manguinhos, do sonho à vida: a ciência na Belle Époque. Rio de Janeiro: COC/Fiocruz; 1990a.

Pereira Passos: um Haussmann tropical: a renovação urbana da cidade do Rio de Janeiro no início do século XX. Rio de Janeiro: Departamento Geral de Documentação e Informação Cultural; 1990b.

BRASIL. Ministério da Justiça e Negócios Interiores. Relatório apresentado ao Presidente da República dos Estados Unidos do Brasil pelo Ministro de Estado da Justiça e Negócios Interiores Epitácio Pessoa. Rio de Janeiro: Imprensa Nacional. 1900.

BRASIL. Ministério da Justiça e Negócios Interiores. Relatório apresentado ao Presidente da República dos Estados Unidos do Brasil pelo Ministro de Estado da Justiça e Negócios Interiores Epitácio Pessoa. Rio de Janeiro: Imprensa Nacional. 1901a.

BRASIL. Presidência da República. Decreto Presidencial N. 4.184 de 30 de Setembro de 1901b.

BRASIL. Presidência da República. Decreto Presidencial N. 4.185 de 30 de Setembro de 1901c.

BRASIL. Ministério da Justiça e Negócios Interiores. Relatório apresentado ao Presidente da República dos Estados Unidos do Brasil pelo Ministro de Estado da Justiça e Negócios Interiores Sabino Barroso. Rio de Janeiro: Imprensa Nacional. 1902a.

BRASIL. Ministério da Justiça e Negócios Interiores. Relatório apresentado ao Presidente da República dos Estados Unidos do Brasil pelo Ministro de Estado da Justiça e Negócios Interiores J.J. Seabra. Rio de Janeiro: Imprensa Nacional. 1905.

CALMETTE, A. Do papel dos insetos na propagação das moléstias dos países quentes, Brazil-Medico, Rio de Janeiro, no 29, p. 282-283 ago. 1899.

CAMUS, A. A Peste. São Paulo: Companhia das Letras, 2010. 
CASTRO SANTOS, L. A. de. Power, Ideology and Public Health (1889-1930). Ph. D. Thesis, Harvard University, 1987.

HIRST, L. The conquest of plague: a study of the evolution of epidemiology. Oxford: Clarendon Press, 1953.

HOCHMAN, G. A era do saneamento: as bases da política de saúde pública no Brasil; 3a ed, São Paulo: Hucitec, 2013.

HOWARD-JONES, N. The scientific background of International Sanitary Conferences, 1851-1938. Genebra: World Health Association, 1975.

LOBO, E. M. L. História do Rio de Janeiro (Do capital comercial ao capital industrial e financeiro). Rio de Janeiro: IBMEC, 1978.

MACKOWIAK, P. A. The origin of quarantine. Journal of Clinical Infectious Disease. (2002) 35 (9): p. 10711072.

MONOD, H. Conférence Sanitaire Internationale de Paris de 1903. Melun: Imprimerie Administrative, 1904.

NASCIMENTO, D. R. La llegada de la peste al Estado de Sao Paulo en 1899. Dynamis, vol 31, $n^{\circ} 1$, Granada, 2011.

NASCIMENTO, D. R; SILVA, M. A. D. da. Não é meu intuito estabelecer polêmica: A chegada da peste ao Brasil: análise de uma controvérsia (1899). História, Ciências, Saúde-Manguinhos, v. 20, p. 1271-1285, 2013a. .

A peste bubônica em Portugal e Brasil: uma análise comparada (1899-1906). Vozes, Pretérito \& Devir: revista de História da UESPI, Teresina, v. 1, p. 21-32, 2013 b.

NERY, M. A peste bubônica, Brazil-Médico, Rio de Janeiro, n 8, p. 65-66, fev. 1897.

PINTO, J.. [Carta]. Jornal do Commercio, Rio de Janeiro. 24 ago. 1899a, Gazetilha, p.1.

[Carta]. Jornal do Commercio, Rio de Janeiro. 5 set. 1899b, Gazetilha, p.1.

RIBELO, F. Entre o Carlos R. e o Orleannais: a saúde marítima no relato de dois casos de navios de imigrantes no porto do Rio de Janeiro, 1893-1907. História, Ciências, Saúde-Manguinhos, Rio de Janeiro, v. 20, nํ, julset, 2013,p. 765-796.

SANTOS. Associação Comercial. Relatório apresentado pela Diretoria a Assembleia Geral. Ano de 1900. São Paulo, Tipografia Rosenhaim e Meyer, 1902.

SEIDL, Carlos. A peste nas Índias, relatório do Dr. Yersin, Brazil-Medico, Rio de Janeiro, no 4, p. 33, 1898.

SILVA, M. A. D. da. A representação social da peste bubônica no Rio de Janeiro (1899-1901). Caderno Universitário de História, v. 19, 2012, p.5-10.

. "O baile dos ratos": a construção sociotécnica da peste bubônica no Rio de Janeiro (1897-1906). 2015. 154 f. Dissertação (mestrado) - Faculdade de Filosofia, Letras e Ciências Humanas, Universidade de São Paulo, São Paulo, 2015.

SILVA JUNIOR, M. Peste bubônica. Rio de Janeiro: Jornal do Commercio, 1942.

SIMOND, .P.. La propagation de la peste, Annales de l'institut Pasteur, Paris, № 12, p. 625-687, 1898.

STEPAN, N. Gênese e evolução da ciência brasileira. Rio de Janeiro: Artenova, 1976. 
YERSIN, A; SIMOND, P. Les épidémies de peste en Extrême-Orient, XIIle Congrès International de Médecine, Paris, 1900. Section de médecine et de chirurgie militaires. Sous direction coloniale. Paris, Masson, 1901, p. 16. 